\title{
Peramalan Penggunaan Penyaringan Air Laut Menjadi Air Tawar di PT. ABC Kota Dumai
}

\author{
Hanifatul Rahmi \\ Program Studi Teknik Industri, Sekolah Tinggi Teknologi Dumai \\ Jl. Utama Karya, Bukit Batrem, Dumai Timur, Kota Dumai, Riau 28826 \\ Email: aorrariza89@gmail.com
}

\begin{abstract}
ABSTRAK
Tujuan dari penelitian ini adalah untuk menentukan jumlah permintaan penyaringan yang digunakan untuk menyaring air laut menjadi air tawar di PT ABC Kota Dumai. Metode peramalan permintaan yang digunakan dalam penelitian ini adalah Time Series dengan metode Nä̈ve, Moving Average dan Linear Trend. Pengolahan data dilakukan dengan menggunakan Software $Q M$ V5. Sample dari penelitian ini adalah filter yang dipakai pada Sea Water Reverse Osmosis pada PT ABC Kota Dumai pada bulan April 2020 sampai dengan Agustus 2020. Hasil pengujian dengan metode Linear Trend memiliki nilai kesalahan terkecil MAPE yaitu 15,138\%, MAD sebesar 1,28 dan MSE 2,64. Hal ini menunjukkan bahwa metode Time Series yang terbaik untuk meramal permintaan filter dalam proses Sea Water Reverse osmosis karena memiliki nilai kesalahan yang kecil dibandingkan metode Naïve dan Moving Average.
\end{abstract}

Kata kunci: Penyaringan Air Laut, Metode Time Series

\section{ABSTRACT}

The purpose of this study is to determine the number of filtering requests used to filter sea water into fresh water in PT ABC City of Dumai. Demand forecasting method used in this research is Time Series with Naïve, Moving Average and Linear Trend methods. Data processing is performed using QM V5 Software. The sample of this research is the filter used in Sea Water Reverse Osmosis at PT ABC Dumai City in April 2020 to August 2020. The results of testing using the Linear Trend method have the smallest MAPE error values of $15.138 \%$, MAD of 1.28 and MSE 2, 64. This shows that the Time Series method is the best for predicting filter requests in the Sea Water Reverse osmosis process because it has a small error value compared to the Naïve and Moving Average methods.

Keywords: Filtering, sea water, Time Series Method 


\section{Pendahuluan}

Air adalah kebutuhan dasar dalam pabrikasi yang paling penting. Namun tidak semua daerah mempunyai sumberdaya air yang baik. Wilayah pesisir pantai dan pulau-pulau kecil di tengah lautan lepas merupakan daerah-daerah yang sangat miskin akan sumber air tawar, sehingga timbul masalah pemenuhan kebutuhan air. Sumberdaya air yang terdapat di daerah tersebut umumnya berkualitas buruk, misalnya air tanahnya yang payau atau asin. Sumber air yang secara kuantitas tidak terbatas adalah air laut, walaupun kualitasnya sangat buruk karena banyak mengandung kadar garam atau TDS (Total Dissolved Solid) sangat tinggi. Hal tersebutlah yang terjadi daerah Dumai yang merupakan daerah pesisir pantai yang kurang ketersediaan sumber air bersih. Untuk mengatasi masalah tersebut PT ABC yang merupakan perusahaan industri yang bergerak dibidang pengolahan kepala sawit melakukan pengaringan air laut ribuan liter dengan model destilasi setiap harinya. Dalam produksi ini membutuhkan penyaringan yang tidak boleh berhenti karena perusahaan akan merugi dan juga penghematan biaya pengiriman dengan pemesanan filter yang pas. Selain itu juga, menghindari terlalu banyak pesanan sehingga memenuhi gudang dan mengurangi resiko barang rusak di gudang. Berdasarkan hal tersebut penulis tertarik untuk melakukan penelitian tentang peramalan permintaan penggunaan penyaringan air laut menjadi air tawar pada sea water osmosis dengan menggunakan metode times series.

\section{Metode Penelitian}

Objek dari penelitian ini adalah filter yang dipakai pada Sea Water Reverse Osmosis pada PT ABC Kota Dumai pada bulan April 2020 sampai dengan Agustus 2020. Metode peramalan yang dipakai dalam penelitian ini adalah time series dengan metode Naïve, Moving Average dan Linear Trend. Langkah-langkah penelitian yang dilakukan sebagai berikut:

1) Tahap identifikasi masalah

Pada tahap ini dilakukan analisis terhadap permasalahan ketersediaan filter yang dipakai pada Sea Water Reverse Osmosis.

2) Tahap perumusan masalah

Pada tahap ini peneliti merumuskan masalah yang akan diteliti sehingga mempermudah dalam penentuan tujuan penelitian dan proses secara sisematis

3) Penentuan Tujuan Penelitian

Penentuan tujuan penelitian agar peneliti fokus pada masalah yang akan diteliti yang sudah dirumuskan pada identifikasi masalah. Dengan demikian arah penelitian lebih jelas.

4) Studi Lapangan

5) Studi lapangan yang didlakukan dalam penelitian ini adalh melakukan observasi ke alapangan dan mengidentifikasi serta mengungkapkan fakta yang terjadi di lapangan secara mendalam.

6) Studi Kepustakaan

Studi kepustakan dilakuakan untuk mencari infoemasi dan metode-metode yang bisa digunakan untuk menyelesaikan permasalahan tersebut melalui jurnal, textbook, laporan penenlitian sebelumnya.

7) Pengumpulan Data 
Pengumpulan data dilakukan dengan menganalisis arsip buku permintaan dari bulan April 2020 sampai Agustus 2020.

8) Hasil Peramalan

Hasil analisis pengolahan data permintaan bulan april 2020 sampai agustus 2020 dengan menggunakan metode time series degan software POM QW for Windows versi 5.

9) Rekapitulasi nilai error dan hasil peramalan terbaik

10) Hasil permintaaan dengan menggunakan metode terbaik ditentukan berdasarkan nilai error yang terkecil.

11) Kesimpulan dan saran

Setelah melakukan analisis terhadap data hasil penelitian selanjutnya dapat ditarik kesimpulan dan saran pernbaikan dimasa yang akan datang.

\section{Hasil dan Pembahasan}

Pengumpulan data berdasarkan pembukuan pemakaian yang dimulai dari bulan April 2020 sampai dengan bulan Agustus 2020 dapat dilihat pada tabel 1.

Tabel 1. Data Pemakaian Filter Sea Water periode April-Agustus 2020

\begin{tabular}{|l|l|}
\hline Bulan & Jumlah filter \\
\hline April & 8 \\
\hline Mei & 10 \\
\hline Juni & 7 \\
\hline Juli & 12 \\
\hline Agustus & 14 \\
\hline
\end{tabular}

Berikut adalah cara dan pengolahan data menggunakan QM V5

1. Aktifkan QM V5. Klik menu Module, pilih Forecasting

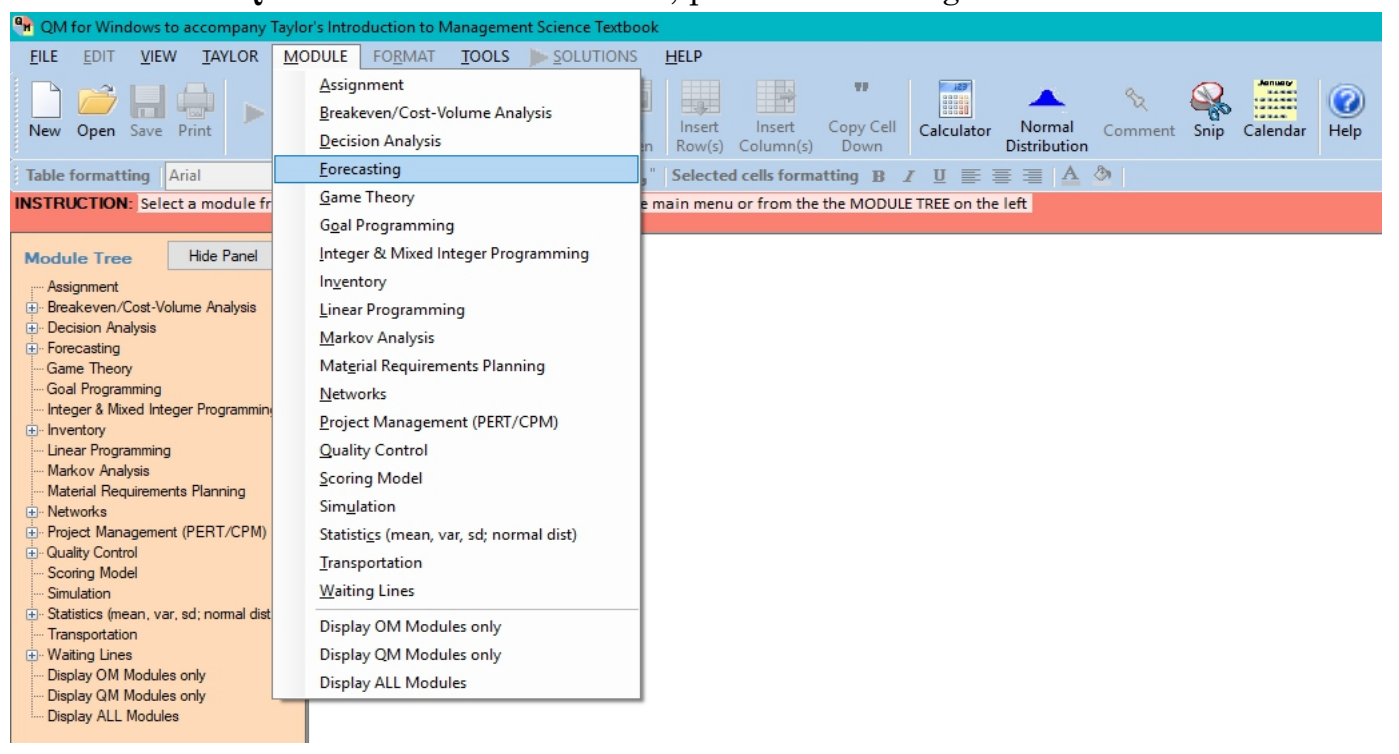


2. Klik File, pilih New dan Time Series Analysis

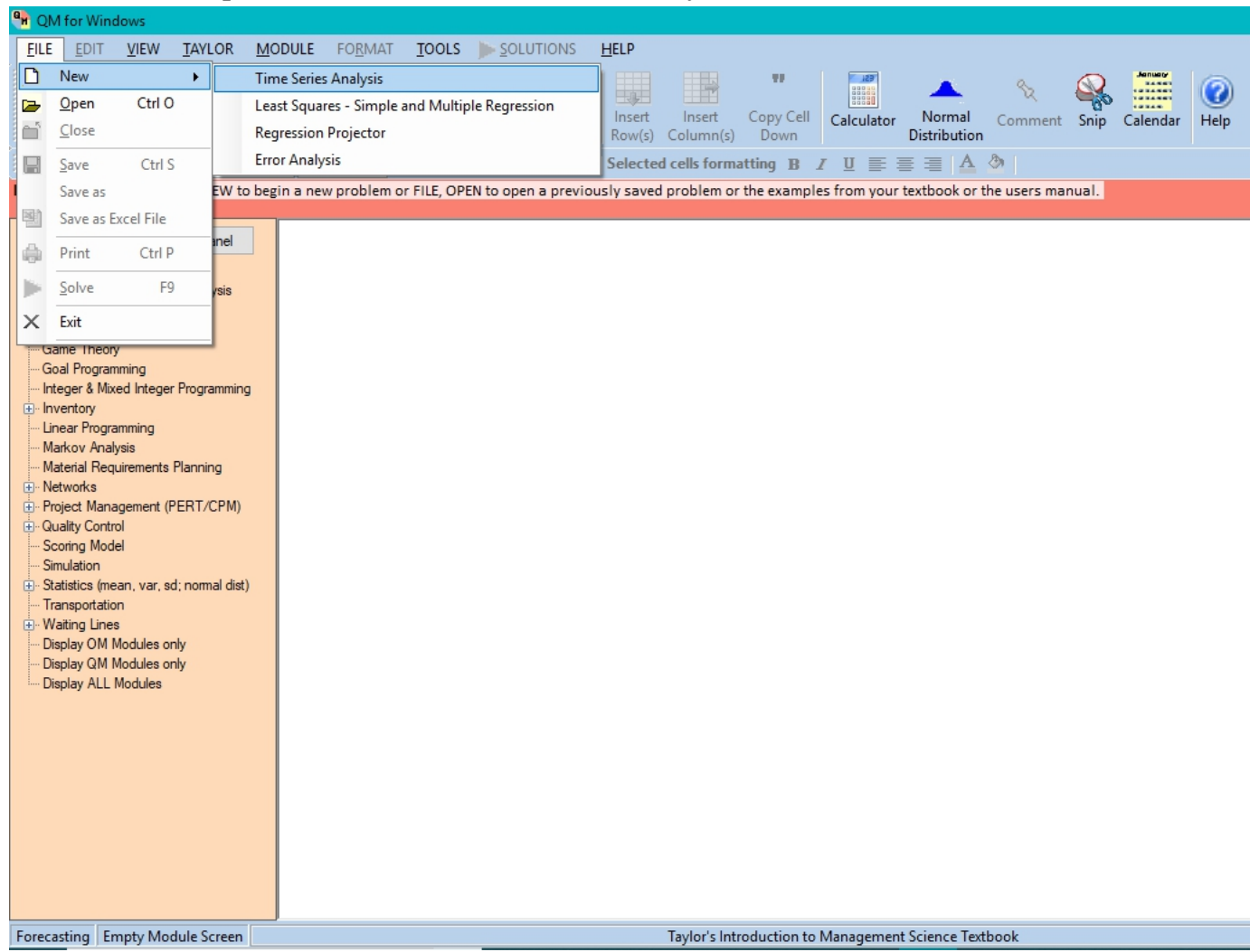

3. Isi kolom Title dengan PT. ABC dan isi Number of Past Periode ubah menjadi 5

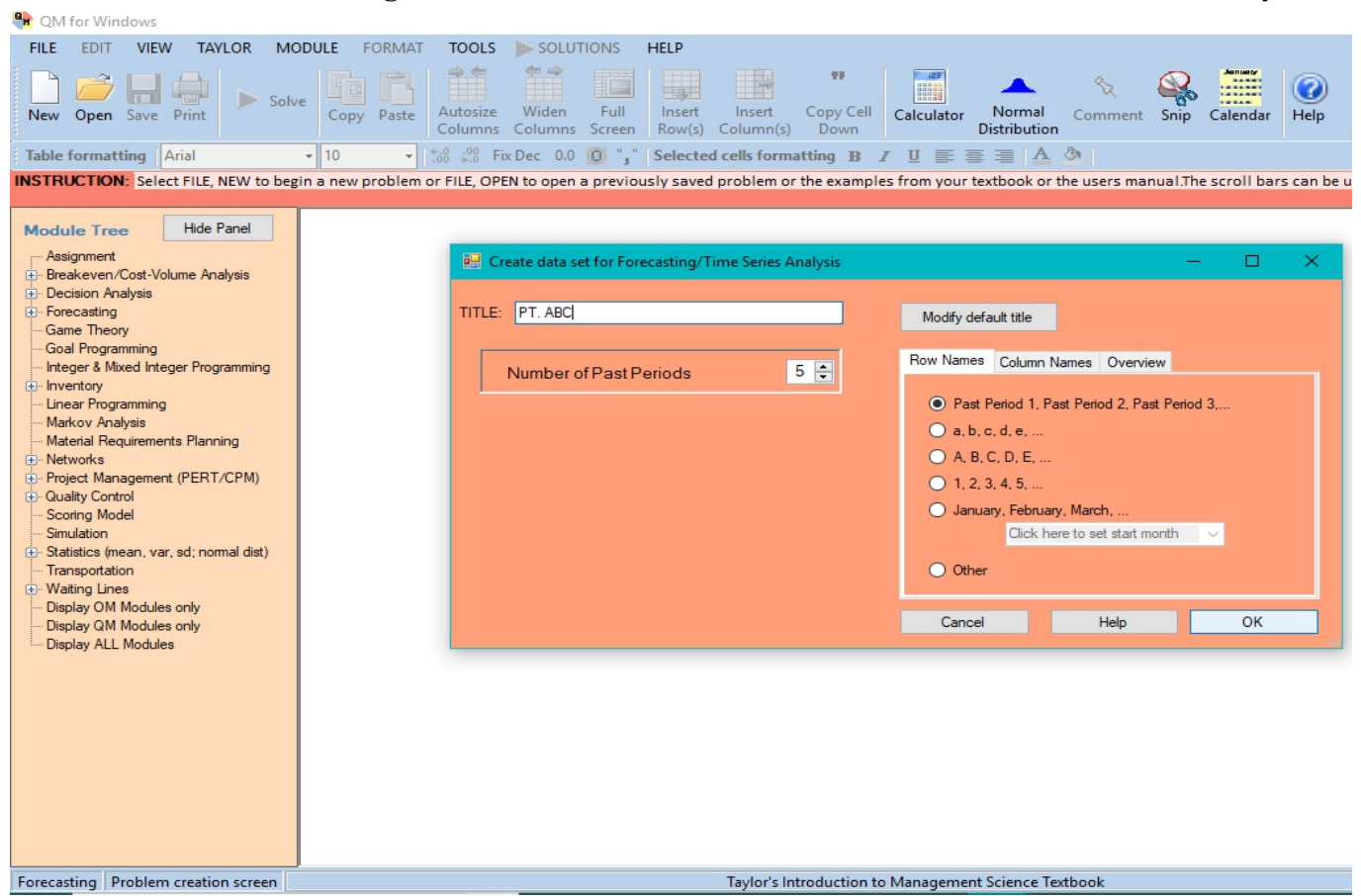


4. Isi kolom berdasarkan data yang diperoleh

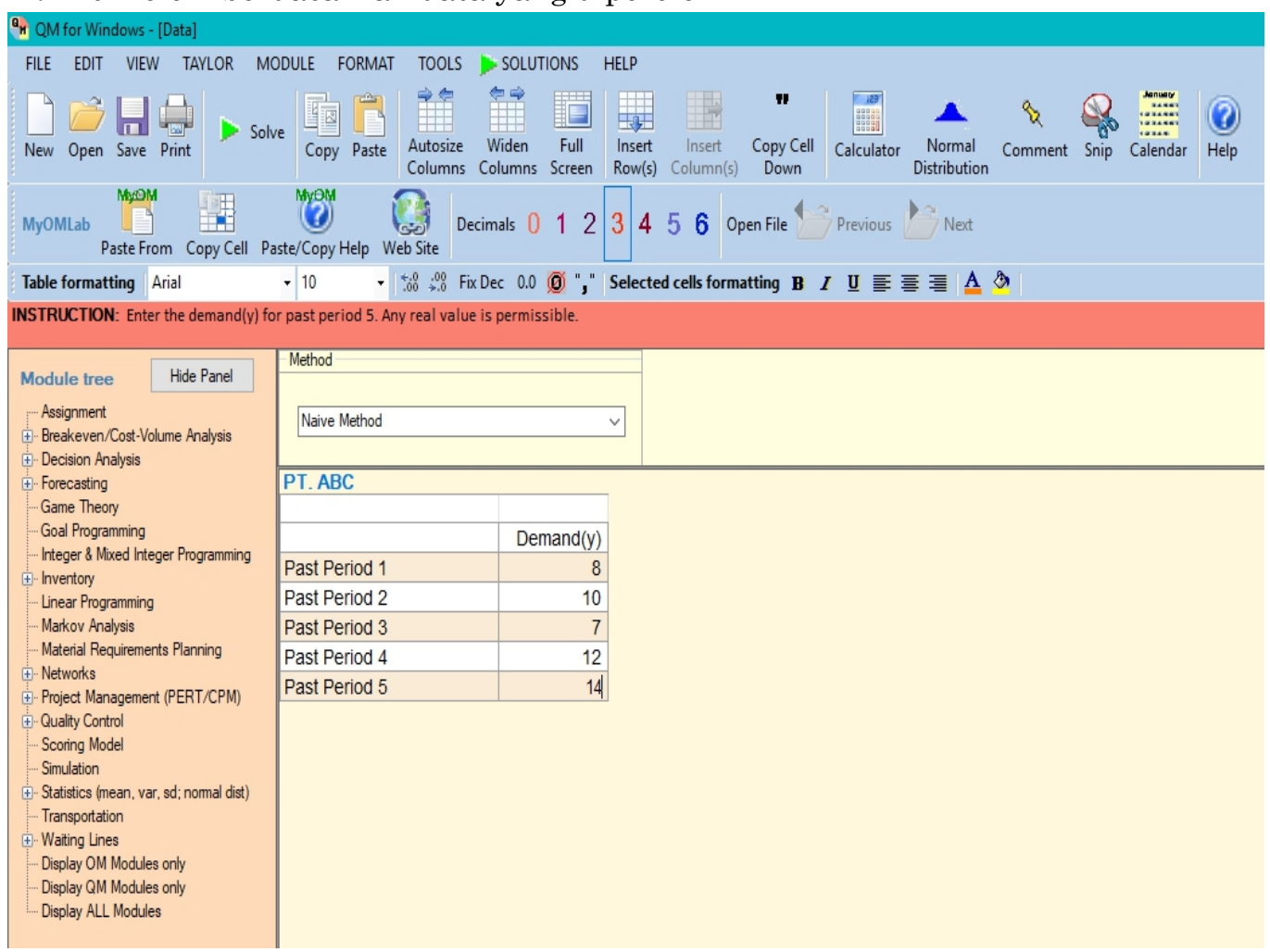

4iv ON for Windows

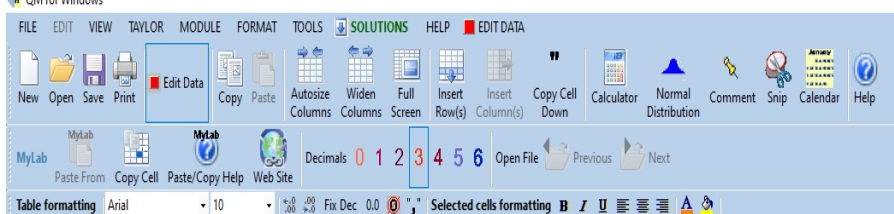

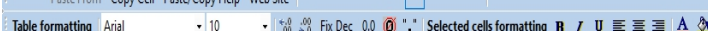

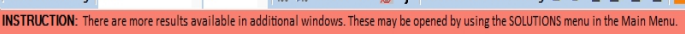

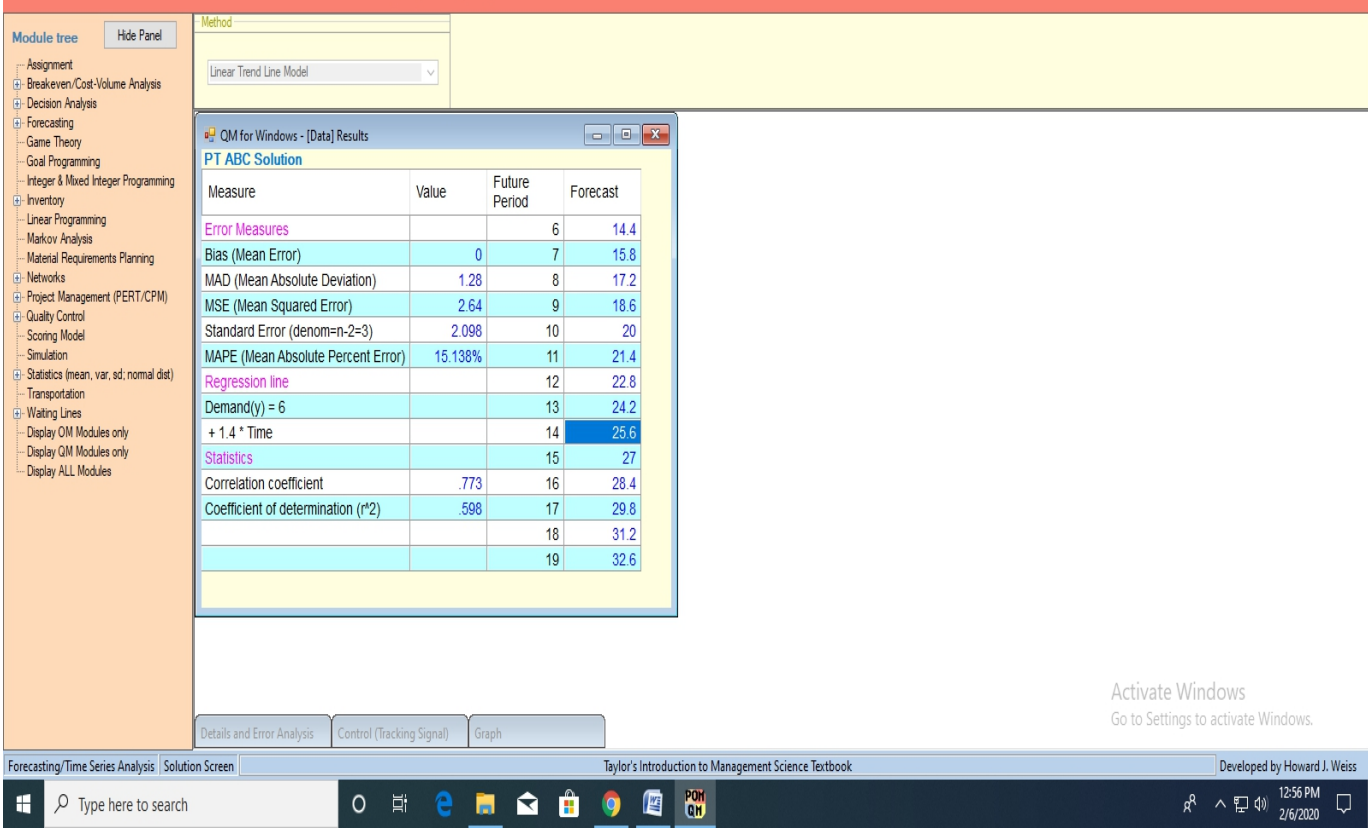


5. Klik Solve

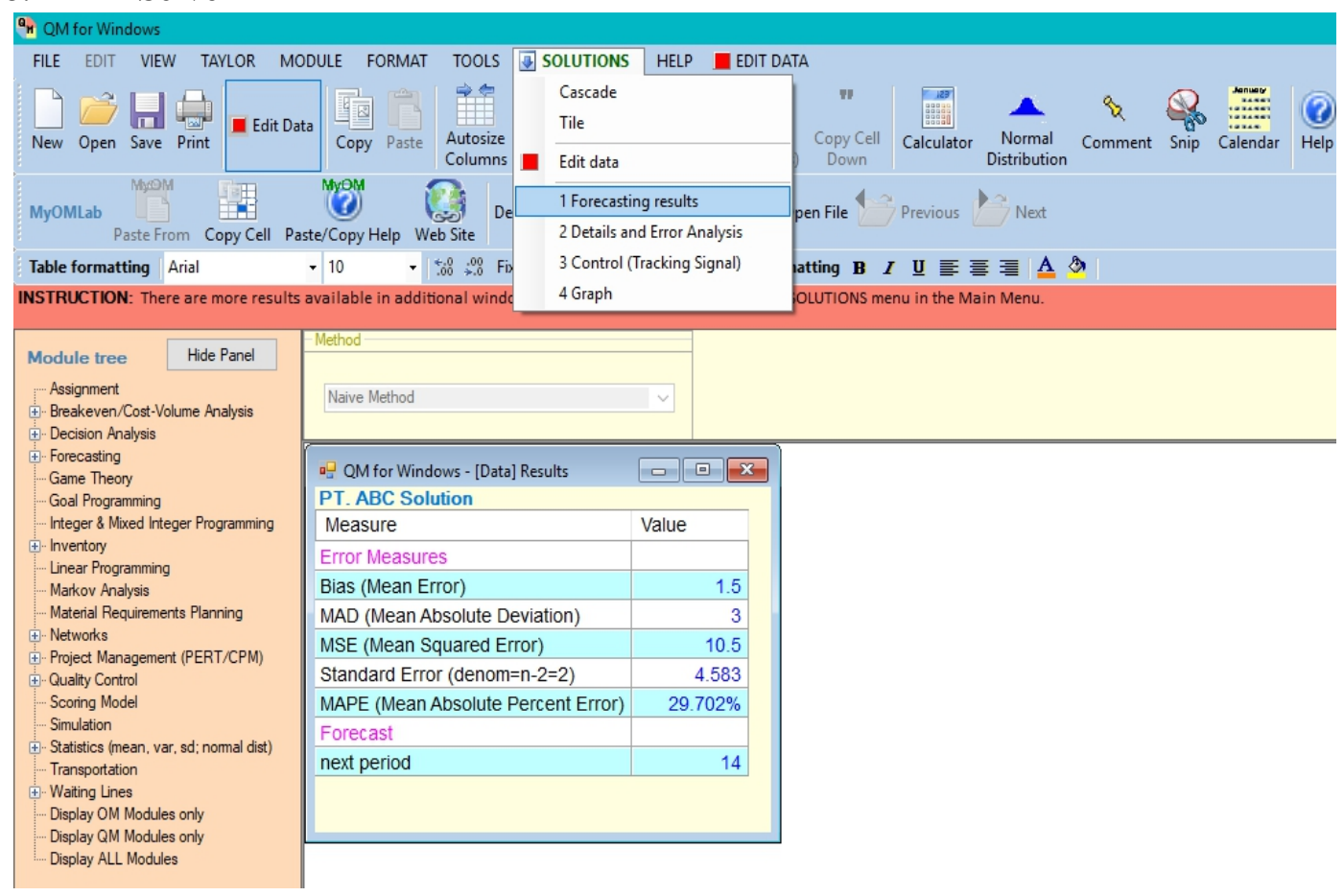

Hasil peramalan pemakaian filter dikumpulkan dari bulan April 2020 sampai dengan Agustus 2020. Analisis yang dilakukan menggunakan software POM QM for windows. Hasil peramalan permintaan dapat dilihat pada tabel 2 di bawah ini:

Tabel 2. Hasil Peramalan Menggunakan Metode Time Series

\begin{tabular}{|l|l|l|l|}
\hline Periode & Naïve & Moving average & Linear Trend \\
\hline September & 14 & 14 & 14,4 \\
\hline Oktober & 14 & 13 & 15,8 \\
\hline November & 14 & 11 & 17,2 \\
\hline Desember & 14 & 10,75 & 20 \\
\hline
\end{tabular}

Rekapitulasi nilai error dari tiap metode digunakan unutk mengetahui kevalidan dari metode yang telah digunakan. Hasil rekapitulasi nilai error dapat dilihat pada tabel 3.

Tabel 3. Hasil Rekapitulasi Nilai Error dari Metode Time Series

\begin{tabular}{|l|l|l|l|}
\hline & Naïve & Moving average & Linear Trend \\
\hline MAPE & $29,702 \%$ & $29,702 \%$ & $15,138 \%$ \\
\hline MAD & 3 & 3 & 1,28 \\
\hline MSE & 10,5 & 4,583 & 2,64 \\
\hline
\end{tabular}

Berdasarkan hasil rekapitulasi di atas terlihat metode linear trend memiliki nilai kesalahan terkecil yaitu 15,138\%, MAD sebesar 1,28 dan MSE 2,64. Hal ini menunjukkan bahwa metode time series yang terbaik untuk meramal permintaan 
filter dalam proses Sea Water Reverse Osmosis. Hasil peramalan terbaik ditentukan berdasarkan nilai kesalahan terkecil. Berdasarkan rekapitulasi nilai kesalahan terkecil didapat linear trend sebagai metode peramalan permintaan terbaik. Hasil peramalan permintaan dengan metode linear trend dapat dilihat sebagai berikut:

Tabel 4. Hasil Peramalan Permintaan Terbaik

\begin{tabular}{|c|c|c|c|c|}
\hline Bulan & $\begin{array}{l}\text { Hasil peramalan permintaan } \\
\text { terbaik } \\
\text { (Linear Trend) }\end{array}$ & MAD & MAPE & MSE \\
\hline September 2020 & 14,4 unit & \multirow{4}{*}{1,28} & \multirow{4}{*}{$15,138 \%$} & \multirow{4}{*}{2,64} \\
\hline Oktober 2020 & 15,8 unit & & & \\
\hline November 2020 & 17,2 unit & & & \\
\hline Desember 2020 & 20 unit & & & \\
\hline
\end{tabular}

\section{Simpulan}

Adapun kesimpulan dari penelitian adalah metode peramalan yang terbaik dihasilkan dengan metode linear trend dengan dengan memiliki nilai kesalahan terkecil yaitu 15,138\%, MAD sebesar 1,28 dan MSE 2,64. Hal ini menunjukkan bahwa metode Time Series yang terbaik untuk meramal permintaan filter dalam proses Sea Water Reverse osmosis karena memiliki nilai kesalahan yang kecil dibandingkan metode Naïve dan Moving Average. filtrasi yang dibutuhkan untuk 4 bulan kedepan dari bulan September sampai desember 2020 adalah 15, 16, 18, 20 filter Penggunaan aplikasi QM for windows Versi 5 memudahkan dalam perkiraan jumlah filter yang harus disediakan oleh perusahaan.

\section{Daftar Pustaka}

Amstrong, J.Scott. (2002). Principles of Forecasting : A Handbook for Researchers and Practitioners. New York:Kluer Academic Publishers

Candra S.D (2020). Peramalan Permintaan Produk Handuk dengan Metode Time Series. Skripsi Universitas Muhammadiyah. Surakarta.

Haryati, S. (2014). Sistem Forecasting Perencanaan Produksi pada PD. Adi Anugrah "Food Industry" Tanjungpinang dengan Metode Single Exponential Smoothing. Tanjung Pinang: Universitas Maritim Raja Ali Haji.

Oktoro.O (2017). Peramalan metode exponential smooting dengan POM QM Industrial Enginnering. http://www.youtube.com/watch?v=t4X9639m9gs, diakses pada Oktober 2020

Prihatiningsih,R.D. (2005). Penentuan Metode Peramalan dan Persediaan Pengaman Bahan Baku Produk Ekspor di PT Sri Rejeki Isman Sukoharjo.Fakultas Ekonomi, Universitas Sebelas Maret Surakarta

Yogi, D.G. (2018). Desalinasi Air Laut Berbasis Energy Surya Sebagai Alternative Penyediaan Air Bersih. Jurnal Teknik Mesin (JTM) 07 (1) 